\title{
Case Study: Influence of Morphological Changes on Flooding in Jingjiang River
}

\author{
Ping Fan'; J. C. Liं; Q. Q. Liü; and V. P. Singh, F.ASCE ${ }^{4}$
}

\begin{abstract}
The middle reach of the Yangtze River, customarily called the Jingjiang River, together with its diversion channels and Dongting Lake, form a large complicated drainage system. In the last five decades, significant geomorphological changes have occurred in the drainage system, including the shrinkage of diversion channels, contraction of Dongting Lake, changes in the rating curve at the Luoshan station, and cutoffs of the lower Jingjiang River. These changes are believed to be the cause of the occurrence of abnormal floods in the Jingjiang River. Qualitative analyses suggest that the first three factors aggravate the flood situation in the lower Jingjiang River, while the last factor seems beneficial for flood prevention. To quantitatively evaluate these conclusions, a finite-volume numerical model was constructed. A series of numerical simulations were carried out to test the individual and combined effects of the aforementioned four factors, and these simulations showed that high flood stages in the Jingiiang River clearly are related to the geomorphological changes.
\end{abstract}

DOI: 10.1061/(ASCE)0733-9429(2008)134:12(1757)

CE Database subject headings: Open channel flow; Flood routing; Flow simulation; Channel morphology; Rivers; China.

\section{Introduction}

The Yangtze River is about 6,300 km long, has a drainage area of almost 1.8 million $\mathrm{km}^{2}$, occupies $18.75 \%$ of China's land area, and is the largest river in the country. The middle part of the Yangtze River has a length of $340 \mathrm{~km}$, traditionally is called the Jingjiang River, and its basin includes Dongting Lake (Fig. 1). It starts from Zhicheng, which is $60 \mathrm{~km}$ downstream from the outlet of the Three Gorges (Yichang) and ends at the Chenglingji station where the outlet of Dongting Lake joins the Yangtze River. On the south bank of the Jingjiang River, four rivers emanate from the main stem; from west to east these are the Songzi, Hudu, Ouchi, and Huarong, respectively (the Huarong River was blocked by a manmade sluice in 1958). Dongting Lake, located along the south bank of the Yangtze River, receives discharge not only from the diversion channels of the Yangtze River (Songzi, Hudu, and Ouchi), but also from four other rivers, Xiangjiang, Zishui, Yuanjiang, and Lishui. The Yuanjiang, and Lishui Rivers flow into Dongting Lake from the west, the Zishui River from the southwest, and the Xiangjiang River from the south. This drainage system comprising river networks and lakes is depicted schemati-

${ }^{1}$ Doctor, Institute of Mechanics, Chinese Academy of Sciences, No. 15 Beisihuanxi Rd., Beijing, China 100190. E-mail: fanping@imech. ac.cn

${ }^{2}$ Professor, Institute of Mechanics, Chinese Academy of Sciences, No. 15 Beisihuanxi Rd., Beijing, China 100190. E-mail: jcli05@imech.ac.cn

${ }^{3}$ Professor, Institute of Mechanics, Chinese Academy of Sciences, No. 15 Beisihuanxi Rd., Beijing, China 100190. E-mail: qqliu@imech.ac.cn

${ }^{4}$ Professor and Caroline \& William N. Lehrer Distinguished Chair in Water Engineering, Dept. of Biological and Agricultural Engineering, Texas A \& M Univ., College Station, TX 77843-2117 (corresponding author). E-mail: vsingh@tamu.edu

Note. Discussion open until May 1, 2009. Separate discussions must be submitted for individual papers. The manuscript for this paper was submitted for review and possible publication on October 18, 2005; approved on June 6, 2008. This paper is part of the Journal of Hydraulic Engineering, Vol. 134, No. 12, December 1, 2008. @ASCE, ISSN 07339429/2008/12-1757-1766/\$25.00. cally in Fig. 2. Stations S_Z, S_S, S_J, S_C, S_L, and S_Q correspond to Zhicheng, Shashi, Jianli, Chenglingji, Luoshan, and Qilishan, respectively, while locations O_S, O_H, and O_O correspond to the Songzi, Hudu, and Ouchi outfalls, respectively. Channels S, H, O, L, Y, Z, and X are related, to the Songzi, Hudu, Ouchi, Lishui, Yuanjiang, Zishui, and Xiangjiang Rivers, respectively, while symbols M, S, and E stand, for Muping, South Dongting, and East Dongting Lakes, respectively.

The frequency of floods in the Yangtze River is high. Two of the most serious floods of the last century occurred in 1954 and 1998 with the 1998 flood causing, in economic terms, losses exceeding 200 billion Yuan RMB (Renminbi, Chinese currency) (Zeng and Kong 1999). Although major efforts in the intervening 44 years between these floods were made to strengthen the flood control system of the Yangtze River and strategies to mitigate floods in the Yangtze River basin have been high priorities, the vulnerability to flooding remains high. Table 1 compares the values of maximum flood stage and discharge observed for the 1998 and 1954 floods at four main stations on the Yangtze River. The flood stage corresponding to these two floods was about the same at Zhicheng, but the flood stage for the whole Jingjiang River was significantly higher in 1998 than in 1954, even though the downstream discharge was smaller (Ge et al. 1999). Thus, there is considerable debate on the causes for high flood stages during the 1998 flood in the entire river valley.

Accepting that rainfall and surface flow from the drainage basin were unusually large, changes in the flood storage capacity have become the focus of arguments regarding stages during the 1998 flood. Various reasons for the high flood stages have been advanced, including the reduction in the Dongting Lake area due to sedimentation and land reclamation (Fang and Zhong 2001; Hu et al. 1999; Li et al. 2000, 2003; Su et al. 2001); shrinkage of diversion channels of the Jingjiang River (Ge et al. 1999; Han 1999; Hu et al. 1999; Li and Ni 1998); the cutoffs in the lower Jingjiang River increasing discharge (Duan 1993; Duan et al. 2001; Han 1999; Tang 1999); flood peaks from upstream of the main stream, branches, and Dongting Lake (Zeng and Kong 1999); and change in the water level-discharge relationship at the 


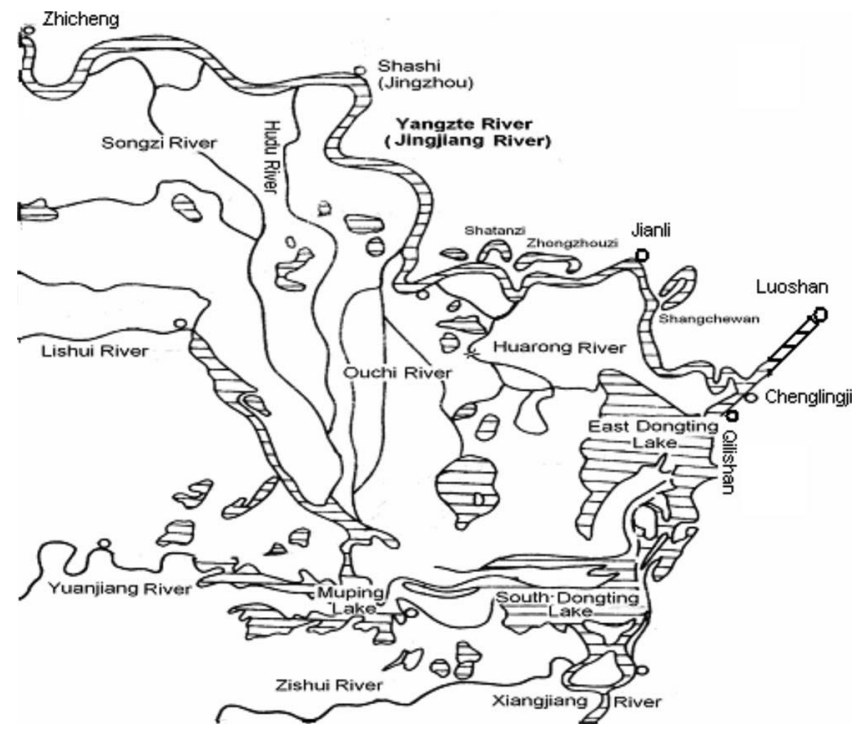

Fig. 1. Location map for the Jingjiang River and Dongting Lake area

Luoshan station (Duan et al. 2001; Ge et al. 1999; Li and $\mathrm{Ni}$ 1998; Li et al. 2000; Zeng and Kong 1999). Furthermore, abnormal weather in the summer of 1998 is regarded as a contributing factor for the high flood stages (Ge et al. 1999).

The reasons for high stages in the Jingjiang River are complex and need further analysis. The main goal of this paper, therefore,

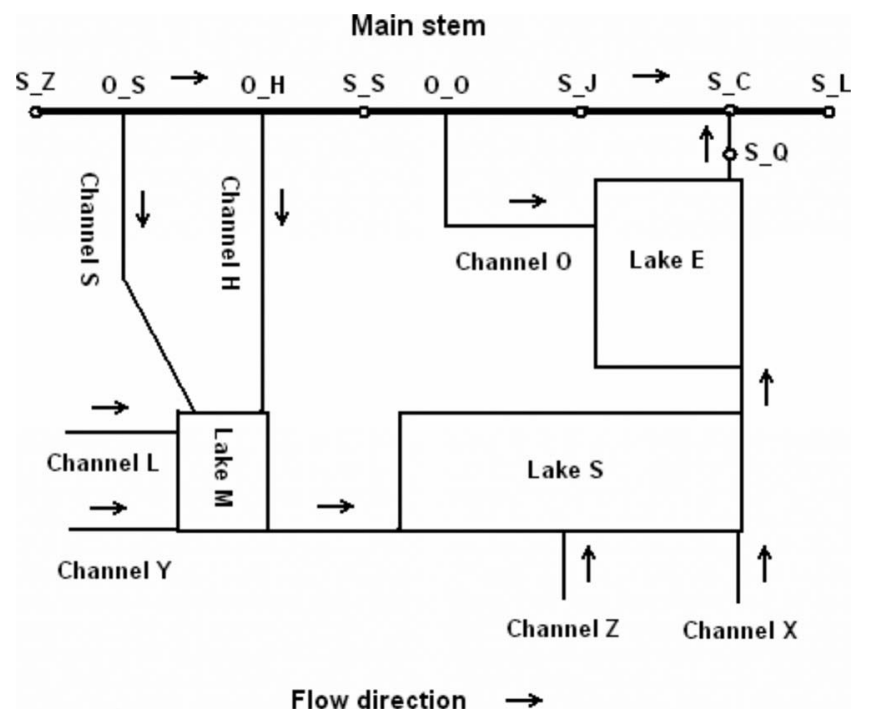

Fig. 2. Sketched river networks characterizing the chief features of Jingjiang River basin is to investigate the relationship between geomorphological changes and high stages in the Jingjiang River. First, the four geomorphological changes are described, and qualitative analyses of their impact on the flood situation are presented. Then, a numerical flood routing model is employed to gain a quantitative understanding of the factors and identify those that would be more crucial for flood prevention in the middle reaches of the Yangtze River. Emphasis here is on the variation in flood levels with the geomorphological changes. The actual channels are very complex, with compound cross sections and bottom topographies, and so simplifications have to be made, preserving the main flow characteristics of the actual drainage system. To that end, the drainage system is considered to consist of one-dimensional rivers and two-dimensional lakes, in which the cross sections of the channels are regarded as rectangular.

Next, a numerical model is developed by introducing a twodimensional junction element and efficiently solving the problem of hydraulic junctions arising in the river network. Although the numerical model is validated with limited hydraulic data, it is found to be capable of simulating the main flow features on the main stem of the actual drainage area. Numerical simulations are carried out to evaluate the individual and combined effects of the aforementioned four geomorphologic changes. Extending the conclusions to the Yangtze River, the relationship between high flood stages and the morphological changes is illustrated.

\section{Morphologic Changes in the Jingjiang River Basin and Dongting Lake Area}

Significant changes have occurred in the Jingjiang River since the 1950 's that may have aggravated flooding. Although the discharge at the upstream station, Zhicheng, and at the downstream station, Luoshan, for the 1998 flood was less than that for the 1954 flood (Table 1), the flood stage, nevertheless, was higher. In particular, the discharge at the Luoshan station was less by $11,000 \mathrm{~m}^{3} / \mathrm{s}$, but the flood stage was higher by $1.78 \mathrm{~m}$. On the other hand, both the flood stage and discharge at Shashi and Jianli in the middle reach of the Jingjiang River for the 1998 flood were greater than those in 1954. Several geomorphological changes in the Jingjiang River basin were investigated to explain the observed aggravated flooding.

\section{Shrinkage of Diversion Channels of the Jingjiang River}

The rivers diverting flow from the Jingjiang River, including the Songzi, Hudu, and Ouchi significantly influence the relation between the Jingjiang River and Dongting Lake (Lu 1996). Table 2 presents the variation in the annual volume of water in the diversion channels in four time periods. The total flow diverted by the three diversion rivers from the Jingjiang River has diminished

Table 1. Comparison of Maximum Flood Stages and Discharges in 1998 and 1954 at Main Stations on the Yangtze River (Data Adapted from CAS 1998)

\begin{tabular}{|c|c|c|c|c|c|c|c|}
\hline \multirow[b]{2}{*}{ Station } & \multirow[b]{2}{*}{$\begin{array}{c}\text { Corresponding } \\
\text { notation in Fig. } 2\end{array}$} & \multicolumn{2}{|c|}{ Maximum value in 1998} & \multicolumn{2}{|c|}{ Maximum value in 1954} & \multicolumn{2}{|c|}{$\begin{array}{l}\text { Maximum value difference } \\
\text { (between } 1998 \text { and 1954) }\end{array}$} \\
\hline & & $\begin{array}{l}\text { Water level } \\
\quad(\mathrm{m})\end{array}$ & $\begin{array}{c}\text { Discharge } \\
\left(\mathrm{m}^{3} / \mathrm{s}\right)\end{array}$ & $\begin{array}{l}\text { Water level } \\
\quad(\mathrm{m})\end{array}$ & $\begin{array}{l}\text { Discharge } \\
\left(\mathrm{m}^{3} / \mathrm{s}\right)\end{array}$ & $\begin{array}{l}\text { Water level } \\
\quad(\mathrm{m})\end{array}$ & $\begin{array}{c}\text { Discharge } \\
\left(\mathrm{m}^{3} / \mathrm{s}\right)\end{array}$ \\
\hline Zhicheng & S_Z & 50.62 & 68,800 & 50.61 & 71,900 & 0.01 & $-3,100$ \\
\hline Shashi & S_S & 45.22 & 53,700 & 44.67 & 50,000 & 0.55 & 3,700 \\
\hline Jianli & S_J & 38.31 & 46,300 & 36.57 & 36,500 & 1.74 & 9,800 \\
\hline Luoshan & S_L & 34.95 & 67,800 & 33.17 & 78,800 & 1.78 & $-11,000$ \\
\hline
\end{tabular}

Note: All observed values, including those in Tables 2-5 and Figs. 1-7, heretofore are indicated from the report by CAS (1998). 
Table 2. Variations of the Annual Amounts of Water and Sediment in the Rivers Diverting Flow from the Jingjiang River (Data Adapted from CAS 1998)

\begin{tabular}{|c|c|c|c|c|c|}
\hline \multirow[b]{2}{*}{ River } & \multirow[b]{2}{*}{ Parameter } & \multicolumn{4}{|c|}{ Water $\left(10^{8} \mathrm{~m}^{3}\right)$} \\
\hline & & 1956-1966 & 1967-1972 & 1973-1980 & $1981-1995$ \\
\hline \multirow[t]{2}{*}{ Songzi } & Value & 490 & 446 & 428 & 374 \\
\hline & Percentage & 10.8 & 10.4 & 9.6 & 8.4 \\
\hline \multirow[t]{2}{*}{ Hudu } & Value & 210 & 186 & 160 & 133 \\
\hline & Percentage & 4.6 & 4.3 & 3.6 & 3 \\
\hline \multirow[t]{2}{*}{ Ouchi } & Value & 652 & 391 & 247 & 187 \\
\hline & Percentage & 14.4 & 9.1 & 5.6 & 4.2 \\
\hline \multirow[t]{2}{*}{ Total (of above three) } & Value & 1,352 & 1,023 & 835 & 694 \\
\hline & Percentage & 29.9 & 23.8 & 18.8 & 15.6 \\
\hline Jingjiang (Zhicheng) & Value & 4,523 & 4,302 & 4,441 & 4,438 \\
\hline Lower Jingjiang & Value & 3,171 & 3,279 & 3,606 & 3,744 \\
\hline
\end{tabular}

Note: Percentage $(P)$ is calculated from the equation, $P=$ value of the channel/value at Zhicheng.

from $29.9 \%$ in $1956-1966$ to $15.6 \%$ in $1981-1995$. The most remarkable variation in the flood diversion capability among the three diversion rivers is for the Ouchi River. The diverted volumes of water have decreased from 14.4 to $4.2 \%$. The reduction in the diversion capability of the three rivers is supposed to be caused by sedimentation and the cutoffs of the lower Jingjiang River that occurred in 1967-1972.

Fig. 3 is a sketch of a simple diversion channel system composed of a main stream and two branches, where $Q_{m}$ and $h_{m}$ denote the discharge and flow depth at the downstream boundary of the mainstream, respectively; $Q_{1}, h_{1}$ and $Q_{2}, h_{2}$ represent the discharge and flow depth at the downstream boundary of the two branches, respectively; and $S_{1}$ and $S_{2}=$ average bed slopes for the two branches, respectively. Fan et al. (2004) suggested that, for a branch, an increase in the bed slope leads to a rise in discharge and a decline in flow depth, i.e.

$$
\frac{\partial Q_{1}}{\partial S_{1}}>0, \quad \frac{\partial h_{1}}{\partial S_{1}}<0, \quad \frac{\partial h_{m}}{\partial S_{1}}<0
$$

Considering the Jingjiang River and its diversion channels as a diversion channel system, it follows from Eq. (1) that an increase in the slope of the lower Jingjiang River results in a decrease in discharge in the diversion channels, which may partially be a consequence of the shrinkage of the diversion channel.

\section{Cutoffs of the Lower Jingjiang River}

The lower Jingjiang River is the section from the Ouchi inlet to the Chenglingji station, and before cutoffs, it had a length of about $245 \mathrm{~km}$. For purposes of reducing the flood stage and shortening the journey for shipping, two artificial cutoffs were made at Zhongzhouzi and Shangchewan in 1967 and 1969, respectively. After the latest natural cutoff that took place in 1972 at Shatanzi,

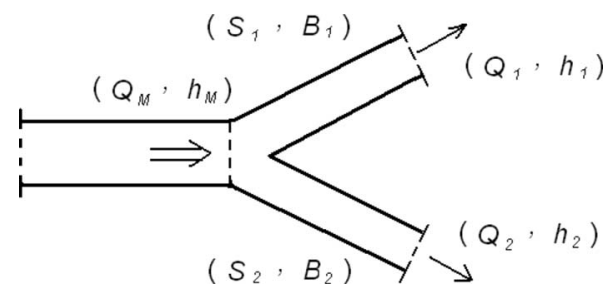

Fig. 3. Conceptual diversion channel system the length of the lower Jingjiang River has been shortened by $74 \mathrm{~km}$ and the reach remains about $170 \mathrm{~km}$ long. This change has enhanced discharge in the lower Jingjiang River (see Table 2) and is hypothesized by many researchers to be the chief reason for the high flood stage for the 1998 flood at the Chenglingji station (Han 1999).

The bed slope of the lower Jingjiang River has become steeper after the cutoffs. Therefore, it follows from Eq. (1) that an increase in bed slope results in an increase in discharge and a decrease in water level for the lower Jingjiang River. In other words, if bed aggradation was not considered, the flood stages in the Jingjiang River for the 1998 flood would not have been higher than those for the 1954 flood, even if discharge was increased after the cutoffs.

\section{Contraction of Dongting Lake}

Dongting Lake, the second largest freshwater lake in China, is located to the south of the middle reach of the Yangtze River. The area of the Dongting Lake valley is about $262,823 \mathrm{~km}^{2}$, which covers $12 \%$ of the area of the Yangtze River basin. Dongting Lake consists of three main parts, which from east to west are Dongting Lake, South Dongting Lake, and West Dongting Lake (MuPing Lake). Dongting Lake is a flood channel-type lake in conjunction with the Yangtze River and the four main rivers in Hunan Province (traditionally, called the Four Branches), namely, the Xiangjiang River, Zishui River, Yuanjiang River, and Lishui River (see Figs. 1 and 2). The outflow from Dongting Lake enters the Yangtze River at the Chenglingji station. The Dongting Lake area and the Yangtze River basin form a large complicated drainage network, in which Dongting Lake stores flood waters from the Yangtze River. However, owing to long-term sedimentation and reclamation of land used for cultivation from the lake, Dongting Lake has been contracting gradually. Table 3 shows the variation in the area and storage of Dongting Lake from 1949 to 1995. For the water level of $33.5 \mathrm{~m}$ in 1949 at Chenglingji, the area of Dongting Lake has decreased from $4,350 \mathrm{~km}^{2}$ in 1949 to $2,623 \mathrm{~km}^{2}$ in 1995 . An obvious conclusion is that a reduction in the lake area inevitably results in a decline in the capacity for receiving flood waters from the Yangtze River.

\section{Change in the Rating Curve at the Luoshan Station}

The flood stage in 1998 at the Luoshan station was higher by $1.78 \mathrm{~m}$ than that in 1954, even though the discharge in 1998 was 
Table 3. Variation of the Area and Storage of Dongting Lake at a Water Level of $33.5 \mathrm{~m}$ at the Chenglingji Station (Data Adapted from CAS 1998)

\begin{tabular}{lcc}
\hline Year & Area & Storage \\
\hline 1949 & 4,350 & 29.3 \\
1954 & 3,914 & 26.8 \\
1971 & 2,820 & 22.8 \\
1978 & 2,691 & 18.6 \\
1995 & 2,623 & 16.7 \\
\hline
\end{tabular}

less by $11,000 \mathrm{~m}^{3} / \mathrm{s}$ than that in 1954 (see Table 1 ). This abnormal relation between water level and discharge at the Luoshan station is an important reason for high flood stages in the lower Jingjiang River. Two explanations for the change in the rating curve at the Luoshan station have been advanced. First, special flood-storage lands near the levees at the Luoshan station have been occupied and, therefore, have lost their storage function (Duan et al. 2001; Ge et al. 1999; Li and Ni 1998; Li et al. 2000; Zeng and Kong 1999). On the other hand, sedimentation is considered as another crucial factor for the abnormal relation between water level and discharge at the Luoshan station during the 1998 flood.

\section{Development of a Numerical Model}

\section{Governing Equations}

Mathematical simulation of flood movement in channel networks mostly has been attempted using implicit finite-difference methods. However, the coefficient matrix of the underlying finitedifference equations is an irregular sparse matrix and the required excessive computer storage may make such methods unattractive. In an attempt to avoid solving large matrices, many investigators have simulated channel networks by decomposition techniques (Fread 1973; Choi and Molinas 1993; Nguyen and Kawano 1995; Feng and Rui 1999; Fekete et al. 2001; Choudhury et al. 2002). In the proposed numerical model, the hydraulic junction problem arising in the computation for large river networks was solved by taking advantage of the finite-volume method (FVM), and thus, computation involving large matrices was avoided.

In the FVM, the governing equations in conservation form (Tan 1992; Zhao et al. 1994, 1996) can be expressed as follows:

- One-dimensional de Saint-Venant equation

$$
\frac{\partial \mathbf{U}}{\partial t}+\frac{\partial \mathbf{F}}{\partial x}=\mathbf{b}
$$

in which $\mathbf{U}=[A, Q]^{T}$ describes the conservation variables; $A=$ cross-sectional area; $Q=$ discharge; $\mathbf{F}=[Q, f]^{T}$ denotes the fluxes in the $x$-direction; $f=\left(h u^{2}+g h^{2}\right) B ; h=$ water depth; $u=$ mean flow velocity component in the $x$-direction; $B=$ river width for the rectangular cross section; $g=$ acceleration due to gravity; $\mathbf{b}=\left[q_{l}, g A\left(S_{0}-S_{f}\right)\right]^{T}=$ source term; $q_{l}$ denotes the unit lateral inflow discharge; $S_{0}=$ bed slope; $S_{f}=$ friction slope; and $t=$ time.

- Two-dimensional de Saint-Venant equation

$$
\frac{\partial \mathbf{U}}{\partial t}+\frac{\partial \mathbf{F}}{\partial x}+\frac{\partial \mathbf{G}}{\partial y}=\mathbf{b}
$$

in which $\mathbf{U}=[h, h u, h v]^{T}=$ conservation variables; $v=$ mean flow velocity component in the $y$-direction; $\mathbf{F}=\left[h u, h u^{2}\right.$ $\left.+g h^{2} / 2, h u v\right]^{T}$ denotes the fluxes in the $x$-direction; G $=\left[h v, h u v, h v^{2}+g h^{2} / 2\right]^{T}=$ fluxes in the $y$-direction; the source term is $\mathbf{b}=\left[0, g h\left(S_{0 x}-S_{f x}\right), g h\left(S_{0 y}-S_{f y}\right)\right]^{T} ; S_{0 x}$ and $S_{f x}=$ bed slope and friction slope components in the $x$-direction, respectively; and $S_{0 y}$ and $S_{f y}=$ bed slope and friction slope components in the $y$-direction, respectively.

Eqs. (2) and (3) describe the shallow water flows in onedimensional channels and two-dimensional river basins or lakes, respectively. However, in the FVM model the key problem is to estimate the normal flux through each side of a cell. Therefore, after discretizing the shallow water wave equations, the approximate Riemann solver, which is based on the characteristic theory, is used to solve the original equations. The variables to be calculated for a two-dimensional (2D) problem are $u, v$, and $h$, while for a one-dimensional (1D) problem the variables are $u$ and $h$.

\section{Discretization of the Governing Equations}

For the whole area, the main stem and diversion channels were divided into 1D meshes, which are designed for a cell-centered scheme. Integration of Eq. (2) over an arbitrary control volume yields

$$
\Delta x \frac{d \mathbf{U}}{d t}=-\sum_{j=1}^{2} \mathbf{F}_{N j}+\Delta x \mathbf{b}
$$

in which $j=$ index for the side of the element; $\Delta x=$ cell length; and $\mathbf{F}_{N j}=$ normal flux at the cell interface in the outward normal direction.

The lakes and junction elements were divided into 2D cells. Integrating Eq. (3) over an arbitrary element $\Omega$, one obtains

$$
A \frac{d \mathbf{U}_{N}}{d t}=-\sum_{j=1}^{m}\left[\mathbf{F}\left(\mathbf{U}_{N}\right) s_{j}\right]+A \mathbf{b}
$$

in which $A=$ area of the element; $\mathbf{U}_{N}$ represents the quantity in the local coordinate system located at the element interface; and $S_{j}$ =length of the side.

\section{Numerical Solution of Normal Flux}

It follows from Eq. (5) that the 2D problem in Eq. (3) can be dealt with as a series of local 1D Riemann problems in the direction normal to the element interface. As a result, an approximate Riemann solver is used here to obtain the numerical flux. The local Riemann problem usually is described as below

$$
\frac{\partial \mathbf{U}}{\partial t}+\frac{\partial \mathbf{F}}{\partial \xi}=\frac{\partial \mathbf{U}}{\partial t}+\mathbf{A} \frac{\partial \mathbf{U}}{\partial \xi}=0
$$

in which $\xi$ denotes the direction on one side of the cell directed to the outward normal; $\mathbf{U}=\mathbf{U}_{L}$ if $\xi$ is less than zero and $\mathbf{U}_{R}$ if $\xi$ is larger than zero; and $\mathbf{U}_{L}$ and $\mathbf{U}_{R}=$ properties on the left and right of the element interface, respectively. For example, in a $2 \mathrm{D}$ problem $\mathbf{U}_{L}$ is $\left(h_{L}, h_{L} u_{L}, h_{L} v_{L}\right)$ and $\mathbf{U}_{R}$ is $\left(h_{R}, h_{R} u_{R}, h_{R} v_{R}\right)$. $\mathbf{A}$ $=d \mathbf{F} / d \mathbf{U}=$ Jacobian matrix, which can be readily evaluated as

$$
\mathbf{A}=\frac{d \mathbf{F}}{d \mathbf{U}}=\left(\begin{array}{lll}
0 & 1 & 0 \\
c^{2}-u^{2} & 2 u & 0 \\
-u v & v & u
\end{array}\right)
$$

where $c^{2}=g h$. The eigenvalues of $\mathbf{A}$ are given by $\lambda_{1}=u-c, \lambda_{2}$ $=u$, and $\lambda_{3}=u+c$, and the eigenvectors $\gamma_{\mathbf{k}}$ are $\gamma_{1}=(1, u-c, v)^{T}$, $\gamma_{2}=(0,0,1)^{T}$, and $\gamma_{3}=(1, u+c, v)^{T}$. Along the characteristic line $\Gamma_{k}$, with the corresponding eigenvectors $\gamma_{k}$ or likewise the eigen- 
values $\lambda_{k}$, the Riemann invariants $R_{k}$ with the corresponding eigenvalue $\lambda_{1}$ are $R_{1}^{(1)}=u+2 c$ and $R_{1}^{(2)}=v$. Similarly, the other Riemann invariants can be obtained as $R_{2}^{(1)}=u$ and $R_{2}^{(2)}=h$ for eigenvalue $\lambda_{2}$, and, $R_{3}^{(1)}=u-2 c$ and $R_{3}^{(2)}=v$ for eigenvalue $\lambda_{3}$.

To numerically determine the flux, two algorithms, known as the flux vector splitting (FVS) and flux difference splitting (FDS) schemes, were developed. Following the FVS scheme, the flux $\mathbf{F}=\mathbf{F}(\mathbf{U})$ can be divided into $\mathbf{F}(\mathbf{U})=\mathbf{F}^{+}(\mathbf{U})+\mathbf{F}^{-}(\mathbf{U})$, the two terms on right-hand side of which correspond to the positive and negative eigenvalues, respectively. Consequently, an approximate solution of the Riemann problem given by Eq. (6) is

$$
\begin{aligned}
\mathbf{F}(\mathbf{U}) & =\frac{1}{2}\left[\mathbf{F}\left(\mathbf{U}_{L}\right)+\mathbf{F}\left(\mathbf{U}_{R}\right)-\int_{\mathbf{U}_{L}}^{\mathbf{U}_{R}}|\mathbf{A}| d \mathbf{U}\right] \\
& =\frac{1}{2}\left[\mathbf{F}\left(\mathbf{U}_{L}\right)+\mathbf{F}\left(\mathbf{U}_{R}\right)-\sum_{k} \int_{\Gamma_{k}}\left|\lambda_{k}\right| \vec{r}_{k} d \xi\right]
\end{aligned}
$$

It is assumed that the integral path $\Gamma_{k},(k=1,2$, and 3), starts from $U_{L}$ to $U_{A}$ and $U_{B}$, and ending at $U_{R}$. In Osher's theory, the eigenvalues for each subcurve are allocated in the sequence of $\lambda_{1}=u$ $-c, \lambda_{2}=u$, and $\lambda_{3}=u+c$. Consequently, the characteristic relationships for each path, respectively, are

$$
\begin{array}{cl}
\Gamma_{1}: & u_{L}+2 c_{L}=u_{A}+2 c_{A}, \quad v_{L}=v_{A} \\
\Gamma_{2}: \quad u_{A}=u_{B}, \quad h_{A}=h_{B} \\
\Gamma_{3}: \quad u_{B}-2 c_{B}=u_{R}-2 c_{R}, \quad v_{B}=v_{R}
\end{array}
$$

For 1D situations, $u_{A}=u_{B}$, and $v \equiv 0$. Therefore, based on the above relationship the quantities $\mathbf{U}_{A}$ and $\mathbf{U}_{B}$ are determined as

$$
\begin{gathered}
u_{A}=u_{B}=\frac{u_{L}+2 c_{L}+u_{R}-2 c_{R}}{2} \\
h_{A}=h_{B}=\frac{1}{g}\left(\frac{u_{L}+2 c_{L}-u_{R}+2 c_{R}}{4}\right)^{2}
\end{gathered}
$$

Eq. (10) shows that the numerical flux can be computed according to the sign of the eigenvalues and characteristics of the upwind scheme. There are 16 possibilities for the numerical flux value (Tan 1992; Zhao et al. 1994, 1996).

\section{Boundary Conditions}

Conditions for a closed boundary were specified as

$$
\begin{gathered}
u_{R}=-u_{L} \\
h_{R}=h_{L}
\end{gathered}
$$

At an open boundary of the domain where physical boundary conditions were to be imposed, it was necessary to solve the boundary Riemann problem. For subcritical flow, three kinds of conditions were, therefore, applied:

1. If the water level $h_{R}$ was given, $u_{R}$ was obtained from the following relation:

$$
u_{R}=u_{L}+2 \sqrt{g}\left(\sqrt{h_{L}}-\sqrt{h_{R}}\right)
$$

2. If the unit-width discharge $q_{R}$ was known, $h_{R}$ and $u_{R}$ were determined from the relation $q_{R}=u_{R} h_{R}$, together with Eq. (12).

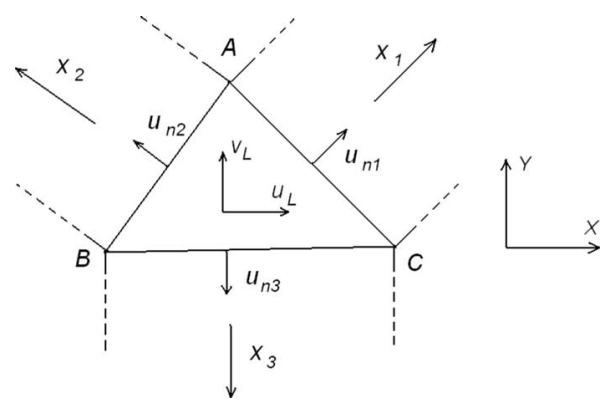

Fig. 4. Triangular joint element

3. When the relation between water depth and unit-width discharge was known, $h_{R}$ and $u_{R}$ were determined from this relation and Eq. (12).

The exterior open boundary conditions were proposed at the two ends of the mainstream and at entries to the lakes. The discharge curve $Q=Q(t)$ was imposed at the upstream end of the mainstream, Station Z, and for Channels X, Z, Y, and L feeding the lakes, respectively. The water level curve $y=y(t)$ or rating curve $Q=f(y)$ was applied at the downstream end of the mainstream, Station L.

\section{Junction Conditions}

A key problem in hydraulic computations for a river network is to solve for hydraulic variables at junctions. With a finite-difference method, a general way is to apply continuous flow conditions and energy conservation conditions at the junction elements. However, this method encounters a difficulty when computing a largescale coefficient matrix, if the number of grid points for the network is large. Thus, many techniques have been developed to reduce the rank of the matrix (Feng and Rui 1999). In this study, the FVM method was applied to solve this junction problem, avoiding calculation of the coefficient matrix, and, thus, simplifying the computation. The essence of this method is that junction elements are considered to be 2D unstructured grids and are computed by the FVM method.

Fig. 4 illustrates a triangular Junction Element ABC, where vectors $x 1, x 2$, and $x 3$ represent the flow directions of channel cells connected to the joint element, respectively; $u_{L}$ and $v_{L}$ $=$ velocity components at the cell's center at the last time step; and $u_{n 1}, u_{n 2}$, and $u_{n 3}=$ flow velocities at the last time step in each channel near Borders $\mathrm{CA}, \mathrm{AB}$, and $\mathrm{BC}$, respectively. In this junction element the hydraulic quantities are assumed to be uniformly distributed so that the quantities at the cell center can be regarded as the left-side variables $\left[\mathrm{U}_{L}\right.$ in Eq. (6)] for each element interface $(\mathrm{AB}, \mathrm{BC}$, and $\mathrm{CA})$. Taking the velocity components $u_{n 1}, u_{n 2}$, and $u_{n 3}$ as the right-side variables $\left[\mathrm{U}_{R}\right.$ in Eq. (6)] for each border, the numerical fluxes across each interface can be calculated via solving the Riemann problem illustrated by Eq. (6). Thus, the hydraulic variables for the whole computing area can be explicitly obtained by implementing the same numerical method, with no need to impose any artificial condition to regulate the discharge distribution between each of the branches connected by the junction. In addition, a joint element can be considered as a quadrangular cell as well and the numerical method is quite similar. Generally speaking, through this method, the quantity of water was conserved and the discharge that flowed from the mainstream 
Table 4. Some Chief Configurations of the Flood Routing Model (Data Adapted from CAS 1998)

\begin{tabular}{|c|c|c|c|c|c|c|c|c|c|c|c|c|}
\hline \multirow[b]{2}{*}{ Parameter } & \multicolumn{5}{|c|}{ Main stem } & \multicolumn{4}{|c|}{ Branch } & \multicolumn{3}{|c|}{ Lake } \\
\hline & $\begin{array}{c}\text { S_Z } \\
\text { to } \\
\text { O_S }\end{array}$ & $\begin{array}{c}\mathrm{O}_{-} \mathrm{S} \\
\text { to } \\
\mathrm{O}_{-} \mathrm{H}\end{array}$ & $\begin{array}{c}\mathrm{O}_{-} \mathrm{H} \\
\text { to } \\
\mathrm{O} \_\mathrm{O}\end{array}$ & $\begin{array}{c}\mathrm{O}_{-} \mathrm{O} \\
\text { to } \\
\mathrm{S}_{-} \mathrm{C}\end{array}$ & $\begin{array}{c}S_{-} C \\
\text { to } \\
S_{-} L\end{array}$ & Channel S & Channel H & Channel O & $\begin{array}{c}\text { S_Q } \\
\text { to } \\
\text { S_C }\end{array}$ & $\begin{array}{c}\text { West } \\
\text { Dongting }\end{array}$ & $\begin{array}{c}\text { South } \\
\text { Dongting }\end{array}$ & $\begin{array}{c}\text { East } \\
\text { Dongting }\end{array}$ \\
\hline Channel length $(\mathrm{km})$ & 50 & 40 & 80 & 170 & 30 & 200 & 150 & 100 & 10 & $10^{\mathrm{b}}$ & $50^{\mathrm{b}}$ & $30^{\mathrm{b}}$ \\
\hline Channel width (m) & 1,500 & 1,500 & 1,500 & 1,500 & 1,500 & 450 & 250 & 400 & 1,000 & $30^{\mathrm{b}}$ & $20^{\mathrm{b}}$ & $40^{\mathrm{b}}$ \\
\hline Bed slop $\left(10^{-4}\right)$ & 0.66 & 0.65 & 0.663 & 0.7 & 0.5 & 0.3 & 0.3 & 0.4 & 0.3 & $0.5^{\mathrm{c}}$ & $0.5^{\mathrm{c}}$ & $0^{\mathrm{c}}$ \\
\hline Bed height $(\mathrm{m})^{\mathrm{a}}$ & 37.1 & 33.8 & 31.2 & 25.9 & 14 & 35.8 & 35 & 30.4 & 15.5 & $0^{\mathrm{c}}$ & $0^{\mathrm{c}}$ & $0.75^{\mathrm{c}}$ \\
\hline
\end{tabular}

${ }^{\mathrm{a}}$ At the upstream end.

${ }^{\mathrm{b}}$ Horizontal dimensions $(\mathrm{km} \times \mathrm{km})$.

${ }^{\mathrm{c}}$ Horizontal slopes in the west-east and south-north directions.

to the branches was allocated automatically. In this manner computation involving a large matrix was avoided and flood routing was done for a complicated river network.

\section{Parameter Estimation and Model Validation}

\section{Geometric Parameters}

The model parameters are of two kinds. The first includes the geometry parameters of channels and lakes. Usually, these parameters are obtained from field surveys and measurements. The drainage system is large and its channels have complex cross sections and bottom topographies. Therefore, for the conceptual channel network system the channel cross sections as well as the lake areas were assumed to be rectangular. Then, most of the geometric parameters were estimated according to the actual ranges that have been observed (see Table 4). Furthermore, in numerical simulations some of the values of geometric parameters were adjusted in order to reproduce the geomorphological changes. For example, before the cutoffs the length of the main stem from $\mathrm{O}_{-} \mathrm{O}$ to $\mathrm{S}_{-} \mathrm{C}$, the river width of channel $\mathrm{O}$, and the total lake area were $250 \mathrm{~km}, 700 \mathrm{~m}$, and $4,500 \mathrm{~km}^{2}$, respectively. However, these values are currently $170 \mathrm{~km}, 400 \mathrm{~m}$, and $2,500 \mathrm{~km}^{2}$, respectively. The channels are discretized into 1D cells with a grid length of $1 \mathrm{~km}$ for each, while the lakes and joint element are divided into 2D meshes. The cell sizes for the lakes are all $1 \mathrm{~km} \times 1 \mathrm{~km}$ and that for the joint elements are determined by the channel widths and the cell sizes of the lakes. Since the model is an explicit numerical method, a time step of $30 \mathrm{~s}$, which is far below the Courant condition, was selected. Hence, stability of numerical simulations is assured.

\section{Hydraulic Parameters}

The other kind of model parameters includes hydraulic parameters, such as the incoming discharge at the upstream boundary, water depth or rating curve at the downstream boundary, and roughness coefficients. The former two mainly are obtained from observed data of the Yangtze flood from July 25 to August 31, 1998 (see Figs. 5 and 6). The roughness coefficient at the main stations is also calibrated to reflect the observed flood stages.

It has been reported by $\mathrm{Hu}$ et al. (1999) that in flood routing simulations for the Yangtze River the roughness coefficient can be selected as 0.025 for the $1 \mathrm{D}$ channels and $0.02-0.025$ for the $2 \mathrm{D}$ lakes, respectively. In this study, it was found that a Manning's roughness coefficient of 0.02 was applicable to most of the channels, except for Channels $\mathrm{S}, \mathrm{H}$, and $\mathrm{O}$, for which the corresponding $n$ values were set as $0.04,0.04$, and 0.023 , respectively. The choice of the roughness coefficient for the main stem of the
Yangtze River lies reasonably in the range suggested previously, while those for the diversion channels are a bit larger.

Simulation results at Stations S_S, S_J, and S_C were compared with observations at Shashi, Jianli, and Chenglingji on the Jingjiang River. Figs. 5 and 6 show the incoming discharge at Station S_Z and flood stage at Station S_L, respectively, from July

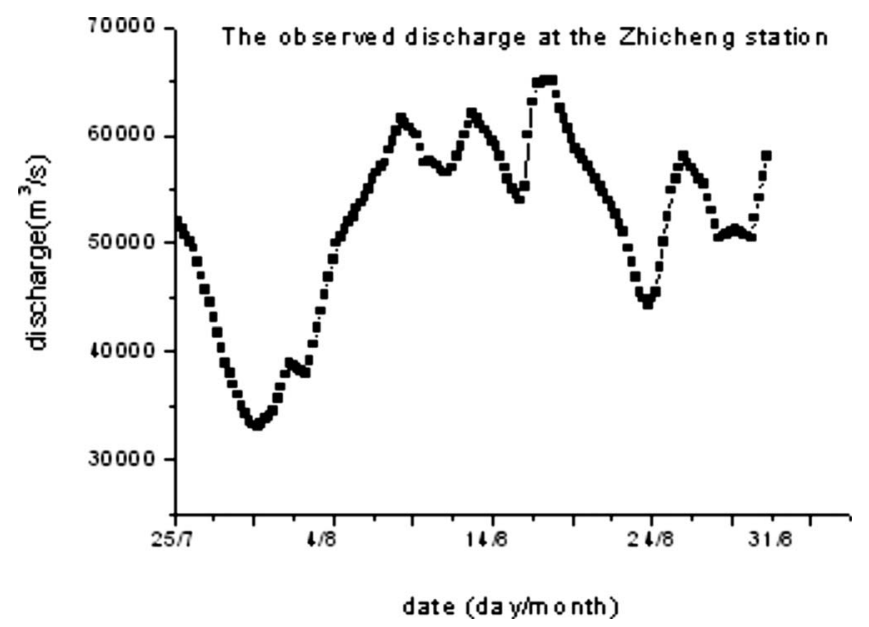

Fig. 5. Observed values of discharge at Zhicheng from July 25 to August 31, 1998 (data adapted from CAS 1998)

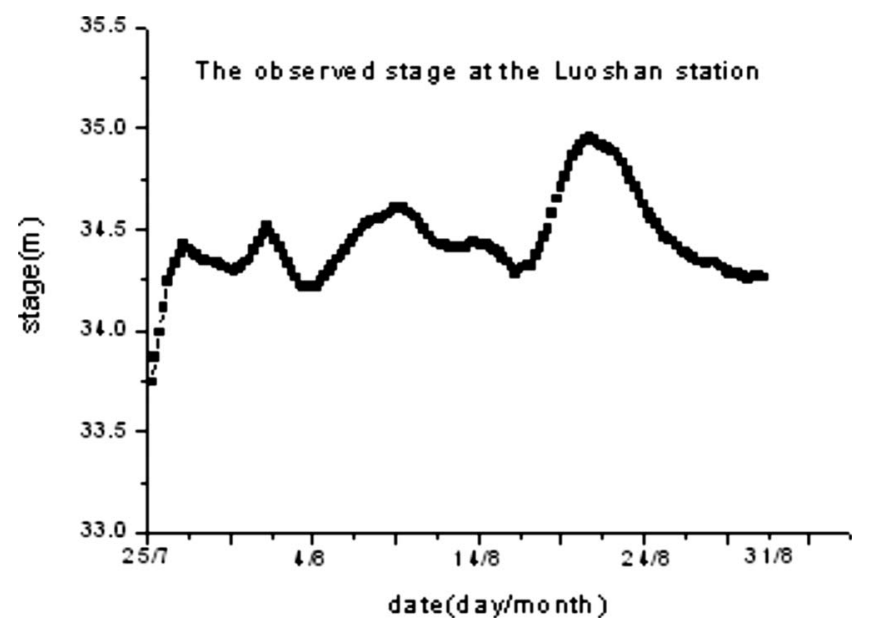

Fig. 6. Observed values of stage at Luoshan from July 25 to August 31, 1998 (data adapted from CAS 1998) 


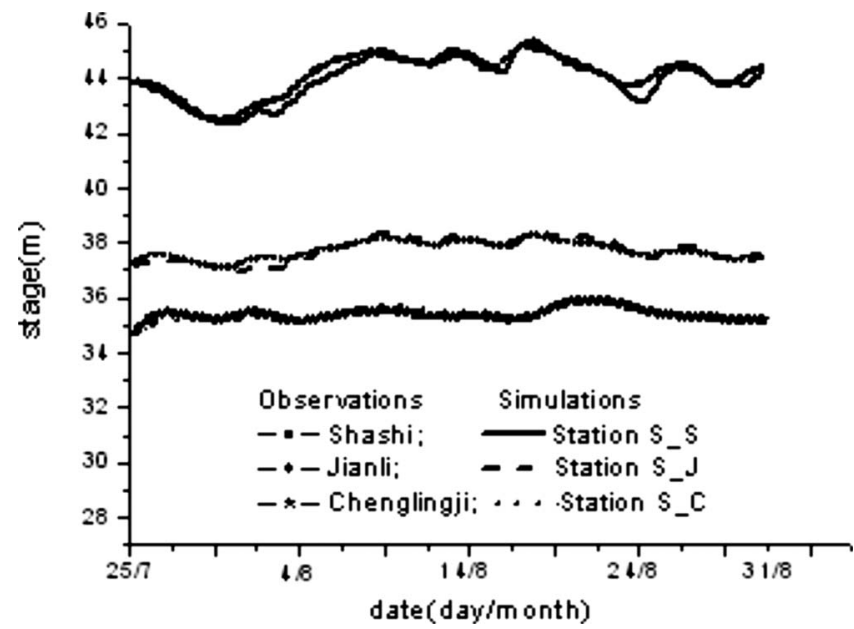

Fig. 7. Comparison of observed flood stages (at Shashi, Jianli, and Chenglingji) and simulated values (at Stations S_S, S_J, and S_C) from July 25 to August 31, 1998 (data adapted from CAS 1998)

25 to August 31. Fig. 7 compares simulated results at Stations S_S, S_J, and S_C with observed water levels at Shashi, Jianli, and Chenglingji, and shows a good agreement between them.

\section{Numerical Experiments}

In this section, parameters, including flood inflows and geomorphological conditions during high flows of the Jingjian River from August 13 to August 31, 1998, were regarded as the basic state. Numerical simulations were performed to reflect the variations in flood stage and discharge for the four morphologic changes. Comparing numerical results with observations for the 1998 flood, the relationship between geomorphologic changes and high stages in the Yangtze River was investigated. A series of cases were chosen to perform simulations for reproducing the corresponding changes in the Jingjiang River in the last four decades.

- Case 1: Flood diversion capabilities of the diversion channels were set back to the level in 1954.

- Case 2: The channel length of the main stem from O_O to S_C was lengthened to the value before cutoffs.

- Case 3: The area of Dongting Lake was enlarged to the value in 1954.

- Case 4: The rating curve at Station S_L was changed to that of 1954.
- Case 5: Considering the combined effects of Cases 1 and 2.

- Case 6: Considering the combined effects of the first four cases.

\section{Individual Effects of the Four Geomorphological Changes}

To attain the diversion capability of the 1954 level, the channel width of the diversion river (mostly for the Ouchi River) was broadened to be doubled. This is equivalent to the effect of reusing the other branch of the Ouchi River (Huarong River), which was blocked in 1958. Simulation was done for Case 1, and the results were compared with the observations for the 1998 flood. Table 5 gives the differences between numerical results and observations. With the enhancement of flood diversion capabilities of diversion channels, the maximum water levels at the Shashi station (S_S), the Ouchi outfall (O_O), and the Chenglingji station (S_C) were found to decrease by $0.53,0.87$, and $0.026 \mathrm{~m}$, respectively. The most significant decline in the maximum water stage occurred at Location O_O, indicating that the Ouchi River (O) experienced the most substantial change among the three diversion channels. From Table 5, it also is found that the maximum discharge in Channel $\mathrm{O}$ and outflow of East Dongting Lake (E) at the Qilishan station (S_Q) increased by 6,381 and $6,010 \mathrm{~m}^{3} / \mathrm{s}$, respectively, after the diversion capabilities of the diversion channels were changed back to the level of 1954. The increase in the influx from Channel O inevitably increases the outflow of Lake E. At the same time, more water diverted to Channel $\mathrm{O}$ results in a decline in discharge in the main stem from O_O to S_C (simplified Main Stem OS). The discharge for the channel downstream from Station S_C slightly alters during this change, as well as does the water stage. Thus, changes in the diversion channels substantially influence the flow near Location O_O but only slightly affect the flow downstream from Station S_C.

The influence of cutoffs on the whole drainage system was numerically simulated in Case 2. Main Stem OS was assumed to be lengthened by $74 \mathrm{~km}$, setting the length back to the value before the cutoffs. Numerical results showed that the maximum water levels at Station S_S, Location O_O, and Station S_C, rose by $0.59,0.95$, and $0.065 \mathrm{~m}$, respectively (see Table 5 and the discharge for Channel $\mathrm{O}$ increased by $2,084 \mathrm{~m}^{3} / \mathrm{s}$. This means that if the length of Main Stem OS returned to the value before the cutoffs, part of the flux in this channel would be diverted to Channel O. Hence, without considering bed aggradation, the cutoffs are beneficial for flood prevention in the main stem, where the stage in Main Stem OS decreased in spite of the increase in discharge. The results also show that the water level at Station

Table 5. Differences between Observations for the 1998 Flood and Numerical Results Obtained for Various Cases (Data Adapted from CAS 1998)

\begin{tabular}{|c|c|c|c|c|c|c|}
\hline \multirow[b]{2}{*}{$\begin{array}{l}\text { Case } \\
\text { number }\end{array}$} & \multicolumn{3}{|c|}{ Difference in maximum water level (m) } & \multicolumn{3}{|c|}{ Difference in maximum discharge $\left(\mathrm{m}^{3} / \mathrm{s}\right)$} \\
\hline & S_S & $\mathrm{O}_{-} \mathrm{O}$ & S_C & $\begin{array}{l}\text { Main stem } \\
\text { from } \mathrm{O}_{-} \mathrm{O} \text { to } \mathrm{S}_{-} \mathrm{C}\end{array}$ & Channel O & S_Q \\
\hline 1 & -0.53 & -0.87 & -0.026 & $-6,132$ & 6,381 & 6,010 \\
\hline 2 & 0.59 & 0.95 & -0.065 & $-2,328$ & 2,084 & 2,580 \\
\hline 3 & -0.046 & -0.077 & -0.283 & -126 & 206 & $-1,315$ \\
\hline 4 & -0.25 & -0.404 & -1.35 & -465 & 470 & 1,058 \\
\hline 5 & 0.006 & 0.039 & -0.053 & $-8,276$ & 8,386 & 8,686 \\
\hline 6 & -0.25 & -0.39 & -1.56 & $-8,287$ & 8,420 & 8,249 \\
\hline Sum of 1 and 2 & 0.06 & 0.08 & -0.091 & $-8,460$ & 8,465 & 8,590 \\
\hline Sum of $1-4$ & -0.236 & -0.401 & -1.727 & $-9,051$ & 9,141 & 8,333 \\
\hline
\end{tabular}


S_C had a small change after the cutoffs. Although the discharge in Main Stem OS increased significantly after the cutoffs, the outflow from Lake E decreased due to the greatly reduced influx from Channel O. Therefore, the total flux at Station S_C almost remained unchanged, and only a slight variation in the water stage occurred.

Numerical results for Case 3 are also given in Table 5. The differences between the maximum simulated and observed water levels for the 1998 flood were $0.046,0.077$, and $0.283 \mathrm{~m}$, respectively, at Station S_S, Location O_O, and Station S_C. The most distinct reduction in the water level occurred at Station S_C, which is different from the other two cases. The maximum outflow from Lake E at Station S_Q is decreased by $1,315 \mathrm{~m}^{3} / \mathrm{s}$ due to the increased lake area. However, discharges in the diversion channels did not increase. Consequently, the contraction of Dongting Lake has a significant effect on the channel stage only downstream of the Chenglingji station.

For Case 4 numerical results indicated that the maximum flood stages at Station S_S, Location O_O, and Station S_C in 1998 declined by $0.25,0.404$, and $1.35 \mathrm{~m}$, respectively, when the rating curve at the Luoshan station (S_L) was restored to the level in 1954 (see Table 5). The flood stages at Station S_C distinctly changed. Thus, the change in the rating curve at Station S_L should be regarded as the most important factor affecting high flood stages in Main Stem OS

\section{Combined Effects of Cases 1 and 2}

In this case, the flood diversion capabilities of the diversion channels and the channel length of Main Stem OS were set back to the values before the cutoffs. Numerical results showed that the maximum water levels on the main stem had only minor variations (see Case 5 in Table 5). The maximum water flux in Main Stem OS decreased, however, by $8,276 \mathrm{~m}^{3} / \mathrm{s}$, while that in Channel O rose by $8,386 \mathrm{~m}^{3} / \mathrm{s}$. The effect of the cutoffs on the water level was offset by that of the declining flood diversion capabilities of the diversion channels. In contrast, the effects of the two changes on discharge were the same. Therefore, the variation of the maximum discharge in Main Stem OS, $8,276 \mathrm{~m}^{3} / \mathrm{s}$, for Case 5 can be approximated by the sum of the individual effects of Cases 1 and 2 , which are 6,132 and $2,328 \mathrm{~m}^{3} / \mathrm{s}$, respectively.

\section{Combined Effects of Cases 1-4}

For Case 6, Table 5 shows that the maximum water levels at Station S_S, Location O_O, and Station S_C declined by 0.25 , 0.39 , and $1.56 \mathrm{~m}$, respectively. The effect of this case is nearly the superposition of the individual effects of Cases 1-4. The effects on discharges are similar. The discharge of Main Stem OS is reduced by $8,287 \mathrm{~m}^{3} / \mathrm{s}$, close to the sum of Cases $1-4$. Furthermore, the superposition approximation is satisfied for the variation of discharge in Channel O. In general, in such a complicated channel network system, it appears that the superposition principle is tenable for studying the impacts of the geomorpholocial changes, which seems to be quite contradictory to the original nonlinear governing equation. This inconsistency may be reasonably accounted for by noting the following characteristics of this model.

First, slopes of this channel network system are fairly gentle $\left(\sim 10^{-5}\right)$. This fundamental characteristic indicates that the flood movement in such a system can be approximated well by the diffusive wave theory of flood routing, and hence, the original two governing equations can be combined to a linear diffusive wave equation, given by (in terms of discharge) (see, for instance, Fan and Li 2006)

$$
\frac{\partial Q}{\partial t}+C \frac{\partial Q}{\partial t}=D \frac{\partial^{2} Q}{\partial x^{2}}+C q_{l}-D \frac{\partial q_{l}}{\partial x}
$$

where $Q=$ discharge; $C=B^{-1} d Q / d h ; D$ denotes the celerity and diffusion coefficient of the flood wave; and $q_{l}=$ lateral inflow. Eq. (13) is still nonlinear, as coefficients $C$ and $D$ are functions of discharge or water level. Therefore, at this stage, we can hardly conclude, that the linear superposition principle is applicable effectively in this system. However, consideration of two more factors makes the approximation of superposition tenable. Under the assumption of a rectangular cross section of the channels, the coefficients for celerity and diffusion of the diffusive wave equation can be expressed as $C=B^{-1} d Q / d h$ and $D=Q /\left(2 B S_{f}\right)$. On the other hand, one can notice that in the specific period considered in the numerical experiments (August 13-31) the fluctuations of the discharge and water stage are relatively insignificant, which are principally $10,000 \mathrm{~m}^{3} / \mathrm{s}$ and $1 \mathrm{~m}$, respectively. This implies that substitution of the average values of the $Q$ and $h$ into the expressions of $C$ and $D$ would not bring about marked errors. In other words, the diffusive equation can be linearized accordingly, and thus the linear superposition principle at least stands for this special problem.

\section{Summary and Discussions}

This study investigated the connection between the geomorphological changes in the Jingjiang River basin and the variation in flood situations. Qualitative analyses indicate that the changes, including the shrinkage of diversion channels, contraction of Dongting Lake, and changes in the rating curve at the Luoshan station, aggravate the flood situation in the Jingjiang River. Also, the cutoffs of the lower Jingjiang River are found to be beneficial for local flood prevention.

To facilitate the simulation of the movement of flood waves in a channel network system, a numerical method was developed by taking advantage of the characteristics of the FVM. Regarding the junctions of the channel branches as 2D elements and calculating the flood movement with a 2D FVM, computation for the whole domain can be done explicitly with the same numerical method. As a consequence, the burden of the traditional computation process for a large-scale matrix is avoided and, hence, the simulation gets to be much efficient.

Numerical simulations, based on a simplified representation of the river network system, confirm the conclusions yielded by the qualitative analyses. They also show that the superposition principle is applicable for separate and combined effects of the four geomorphological factors. The shrinkage of the diversion channels and the cutoffs of the lower Jingjiang River have a significant impact on flow near the Ouchi outfall, while the contraction of Dongting Lake and changes in the rating curve at the Luoshan station dominate the river stage near the Chenglingji station. The shrinkage of diversion channels is largely induced by sediment deposition, while the latter two are caused not only by sediment deposition but also by land encroachment. If the sediment deposition is not taken into account, the cutoffs help reduce the flood stage of the lower Jingjiang River. However, increased sediment deposition downstream from the Chenglingji station is 
caused by cutoffs, and hence, it partly counteracts the positive effect of cutoffs.

Furthermore, in 1998 the lands along the levee near the Luoshan station earmarked for storage of flood waters were not allowed to perform their intended function, according to the government's decision, for fear of likely larger economic losses. The diverted volume of the flood waters amounted to only 6 billion $\mathrm{m}^{3}$ in 1998; however, it was 102.3 billion $\mathrm{m}^{3}$ in 1954 (including that due to levee breaching). If the diverted flood had returned to the river, the flood stage in 1954 would rise by $2 \mathrm{~m}$ at the Luoshan station ( $\mathrm{Li}$ 1999). Thus, reduced flood diversions resulted in a changed rating curve and high stage at the Luoshan station. The stage at the Chenglingji station and even at the Jianli station and the Ouchi outfall were highly elevated. Implications of these analyses could help develop measures for flood prevention in the Jingjiang River basin, which are the cropland should be returned to the lake and the lake area should be enlarged for flood storage; the polder levees along the middle reach of the Jingjiang River should be removed for flooding.

In the end, the precondition for the approximate satisfaction of the superposition principle in this study is worthy of recapitulation. The characteristic of mild channel slopes leads to the flood wave being able to be described by one advection-diffusion equation. Furthermore, the minor fluctuations of the hydraulic element $(Q$ and $h$ ) in the considered flood period ensure that the linearization of the diffusive wave equation becomes feasible. These two criteria also may be helpful to other problems where a complicated channel network is to be considered. Under the satisfaction of the superposition principle for a channel network system, any variation of the hydraulic characteristics would not be induced only by the local changes of the channel morphology, but also by the single change of any other channels that are connected with this channel, or their synthetic effects.

\section{Acknowledgments}

Financial support from the National Natural Science Foundation of China under Grant Nos. 10332050 and 10602060 is appreciated.

\section{Notation}

The following symbols are used in the paper:

$$
A=\text { area of cross section; }
$$

$\mathbf{A}^{+}(\mathbf{U})=$ matrix corresponding to the positive eigenvalue of Eq. (5);

$\mathbf{A}^{-}(\mathbf{U})=$ matrix corresponding to the negative eigenvalue of Eq. (5);

$B=$ river width;

$\mathbf{b}=$ source term;

$\mathbf{F}=$ flux in the $x$-direction;

$\mathbf{F}^{+}(\mathbf{U})=$ flux corresponding to positive eigenvalues;

$\mathbf{F}^{-}(\mathbf{U})=$ flux corresponding to negative eigenvalues;

$\mathbf{F}_{N i j}=$ numerical flux at the cell interface on the outward normal direction;

$\mathbf{G}=$ fluxes in the $y$-direction;

$g=$ acceleration of gravity;

$h=$ water depth;

$h_{L}=$ water depth left of the interface;

$h_{R}=$ water depth right of the interface;

$Q=$ flow discharge;
$q_{\mathrm{L}}=$ unit width discharge left of the interface;

$q_{l}=$ unit lateral inflow discharge;

$q_{\mathrm{R}}=$ unit width discharge right of the interface;

$S_{f}=$ friction slope;

$S_{f x}=$ friction slope component in the $x$-direction;

$S_{f y}=$ friction slope component in the $y$-direction;

$S_{0}=$ bed slope;

$S_{0 x}=$ bed slope component in the $x$-direction;

$S_{0 y}=$ bed slope component in the $y$-direction;

$\mathbf{T}(\boldsymbol{\varphi})=$ rotation transform matrix for the coordinate axes;

$\mathbf{U}=$ conservation variable;

$\mathbf{U}_{\mathrm{L}}=$ flux left of the interface;

$\mathbf{U}_{\mathrm{R}}=$ flux right of the interface;

$u=$ mean flow velocity component in the $x$-direction;

$u_{\mathrm{L}}=$ tangential velocity at left of the interface;

$u_{\mathrm{R}}=$ tangential velocity at right of the interface;

$v=$ mean flow velocity component in the $y$-direction;

$\varphi=$ angle between outward direction of the walls and the $x$-coordinate;

$\boldsymbol{\Gamma}_{k}=k$ th characteristic curve;

$\gamma_{k}=k$ th eigenvector; and

$\lambda_{k}=k$ th eigenvalue.

\section{References}

Chinese Academy of Sciences (CAS). (1998). "Reports on the 1998 Yangtze flood." Rep., Institute of Mechanics, Beijing.

Choi, G. W., and Monilas, A. (1993). "Simultaneous solution algorithm for channel network modeling." Water Resour. Res., 29(2), 321-328.

Choudhury, P., Shrivastava, R. K., and Narulkar, S. M. (2002). "Flood routing in river networks using equivalent Muskingum inflow." $J$. Hydrol. Eng., 7(6), 413-419.

Duan, W. Z. (1993). "The relation between the cutoffs in the lower Jingjiang River and water level at Chenglingji." J. Sediment Res., 3, 39-50 (in Chinese).

Duan, W. Z., Zhen, Y. H., and Liu, J. J. (2001). "Causes of water level rising in Chenglingji-Luoshan reach of ChangJiang River." J. Hydraul. Eng., 2, 29-34 (in Chinese).

Fan, P., and Li, J. C. (2006). "Diffusive wave solutions for open channel flows with uniform and concentrated lateral inflow." Adv. Water Resour, 29, 1000-1019.

Fan, P., Li, J. C., and Liu, Q. Q. (2004). "Flood routing models in confluent and diversion channels." Appl. Math. Mech., 25(12), 1333 1343.

Fang, C. M., and Zhong, Z. Q. (2001). "The influence of capacity decrease on flood stages in Dongting Lake and Yangtze River." J. Hydraul. Eng., 11, 70-74 (in Chinese).

Fekete, B. M., Vorosmarty, C. J., and Lammers, R. B. (2001). "Scaling gridded river networks for macroscale hydrology: Development, analysis, and control of error." Water Resour. Res., 37(7), 1955-1967.

Feng, P., and Rui, X. F. (1999). "Method of flood routing for multibranch rivers.” J. Hydraul. Eng., 125(3), 271-276.

Fread, D. L. (1973). "Technique for implicit dynamic routing in rivers with tributaries." Water Resour. Res., 9(4), 918-926.

Ge, S. X., Wang, J., and Xiong, M. (1999). "Genetic analysis of higher stages along middle Yangtze main stem during flood period in 1998." Yangtze River, 30(2), 29-31 (in Chinese).

Han, Q. W. (1999). "Characteristics and fluvial processes of diffluent rivers from Yangtze River to Dongting Lake." J. Yangtze River Sci. Res. Inst., 16(5), 5-8 (in Chinese).

Hu, S. Y., Shi, Y., Qi, C., Wang, Y. T., and Wu, Y. X. (1999). "Systematic analyses on abnormally high flood stages of middle Yangtze River in 1998." Adv. Water Sci., 10(3), 242-250. 
Li, A. T. (1999). "The 1998 Yangtze flood and fight against it." Yangtze River, 30(1), 1-7 (in Chinese).

Li, Y., Deng, J., and Sun, Z. (2003). "A study on the flood storage capacity of Dongting Lake." Int. J. Sediment Res., 18(2), 138-147.

Li, Y. T., Li, R., and Deng, J. Y. (2000). "A study on mechanism of flow and sediment disaster in the middle reach of Yangtze River." J. Natural Disasters, 9(3), 98-105 (in Chinese).

Li, Y. T., and Ni, J. R. (1998). "Influence of sediment transport to water level elevating in the middle reach of Yangtze River." Chin. J. Basic Sci. Eng., 6(3), 215-221 (in Chinese).

Lu, J. Y. (1996). "Study on laws of runoff and sediment diverted from three outfalls on the Jingjiang reach of the Yangtze River." J. Sediment Res., 12, 54-61.

Nguyen, Q. K., and Kawano, H. (1995). "Simultaneous solution for flood routing in channel networks." J. Hydraul. Eng., 121(10), 744-750.

Su, C., Mo, D. W., and Wang, H. (2001). "Evolution of Lake Dongting and its flood disasters." Res. Soil Water Conserv., 8(2), 52-55 (in Chinese).

Tan, W. (1992). Shallow water hydrodynamics, Elsevier, Amsterdam, The Netherlands.

Tang, R. C. (1999). "Impact of river bend cutoff of lower Jingjiang River on the river and Dongting Lake." Yangtze River, 30(4), 20-48 (in Chinese).

Zeng, G., and Kong, X. (1999). "Preliminary study on the causes and countermeasures of the 1954 and 1998 extraordinary Yangtze River flood." J. Catastrophol., 14(4), 22-26 (in Chinese).

Zhao, D. H., Shen, H. W., Lai, J. S., and Tabios, III, G. Q. (1996). "Approximate Riemann solvers in FVM for 2D hydraulic shock wave modeling." J. Hydraul. Eng., 122(12), 692-702.

Zhao, D. H., Shen, H. W., Tabios, III, G. Q., Lai, J. S., and Tan, W. Y. (1994). "Finite-volume two-dimensional unsteady-flow model for river basins." J. Hydraul. Eng., 120(7), 863-883. 